\title{
Colony stimulating factors secreted by irradiated autologous tumor cell vaccines inhibit immunity
}

\author{
Sruthi Ravindranathan*, Sean G Smith, Khue Nguyen, David A Zaharoff \\ From 30th Annual Meeting and Associated Programs of the Society for Immunotherapy of Cancer (SITC 2015) \\ National Harbor, MD, USA. 4-8 November 2015
}

Autologous tumor cell-based vaccines (ATCVs) have a number of potential advantages including multivalency and patient specificity. ATCVs contain many potential antigens, both known and unknown which potentiate polyclonal responses capable of responding to a more diverse population of tumor cells. In addition, because ATCVs are created from a patient's own tumor, all potential immunogenic epitopes are patient specific and each patient is immunized against her complete and individualized antigen repertoire. This is particularly important for breast cancer as each tumor can contain up to 100 different mutant genes so no two tumors are identical.

The major disadvantage of ATCVs, is poor immunogenicity. In order to develop an effective, immunogenic ATCV against breast cancer, we wanted to understand the features of immunogenicity. In this study, BALB/c female mice were given priming and booster vaccinations, ten days apart, with 1 million irradiated (100Gy) EMT6 and/ or 4T1cells. Ten days after the booster vaccination, mice were challenged with live tumor cells. $80 \%$ of mice vaccinated with EMT6 cells were completely protected against a live EMT6 challenge. However, mice vaccinated with irradiated 4T1 cells failed to provide any protection against a live $4 \mathrm{~T} 1$ challenge. Most interestingly, when mice were vaccinated with a mixture of irradiated EMT6 and 4T1 cells at the same site, the protective response against EMT6 challenge was significantly diminished as $60 \%$ of mice developed tumors. Furthermore, when irradiated EMT6 and 4T1 cells were administered on opposite sides, protection from an EMT6 challenge was also significantly diminished with $88 \%$ of mice developing tumors. This finding implied that non-immunogenic irradiated $4 \mathrm{~T} 1$ cells released one or more immunosuppressive factors that inhibited anti-EMT6 immunity.

University of Arkansas, Fayetteville, AR, USA
Thus, we investigated the levels of different immunosuppressive cytokines, G-CSF, M-CSF, GM-CSF, IL-6, MCP1 , TGF- $\beta$ and VEGF released by both 4 T 1 and EMT 6 cells before and after irradiation. Irradiated 4T1 cells secreted high levels of colony stimulating factors. Specifically, at 24 and 48 hours after irradiation, 4T1 cells secreted 60 and $705 \mathrm{pg} / \mathrm{ml}$ of M-CSF; 912 and $5190 \mathrm{pg} / \mathrm{ml}$ of G-CSF; 29 and $180 \mathrm{pg} / \mathrm{ml}$ of GM-CSF. We believe that high levels of colony stimulating factors induce the accumulation of large amounts of myeloid derived suppressor cells (MDSCs) in the tumor site and lymphoid organs which, in turn, suppress anti-EMT-6 immunity. Future studies will determine if blocking colony stimulating factors will decrease the accumulation of MDSCs and subsequently increase anti-tumor immunity.

Published: 4 November 2015

doi:10.1186/2051-1426-3-S2-P448

Cite this article as: Ravindranathan et al: Colony stimulating factors secreted by irradiated autologous tumor cell vaccines inhibit immunity. Journal for ImmunoTherapy of Cancer 2015 3(Suppl 2):P448.

Submit your next manuscript to BioMed Central and take full advantage of:

- Convenient online submission

- Thorough peer review

- No space constraints or color figure charges

- Immediate publication on acceptance

- Inclusion in PubMed, CAS, Scopus and Google Scholar

- Research which is freely available for redistribution 